\title{
Factors determining case fatality in myocardial infarction "Who dies in a heart attack?"
}

Goya Wannamethee, Peter H Whincup, A Gerald Shaper, Mary Walker, Peter W MacFarlane

\begin{abstract}
Objective-To examine the determinants of case fatality in the first major ischaemic heart disease event (heart attack) after screening.

Methods-Prospective study of 7735 middle aged men drawn from general practices in 24 British towns.

Results-During 11.5 years follow up there were 743 major ischaemic heart disease events of which $302(40.6 \%)$ were fatal within 28 days of onset. Previous definite myocardial infarction or stroke and age at time of event were most strongly associated with case fatality. In men with no previous myocardial infarction or stroke, after adjustment for a range of risk factors, antihypertensive treatment (odds ratio $(O R)=1.97$, $P<0.05), \quad$ arrhythmia $(O R=1.93$, $P=0.06)$, increased heart rate $(O R=$ 2.03, $P=0.06)$, and diabetes $(O R=2 \cdot 61$, $P=0.07)$ were associated with increased case fatality. High levels of physical activity $(O R=0.53, P<0.05)$ and $\bmod -$ erate drinking (16-42 units/week) ( $O R=$ $0.61, P<0.05$ ) were associated with lower case fatality, although moderate drinking was not associated with a lower incidence of major ischaemic heart disease events. Current smoking, serum total cholesterol, and systolic blood pressure were not significantly associated with case fatality. In men with previous myocardial infarction or stroke, arrhythmia and to a lesser degree antihypertensive treatment, moderate or heavy drinking, and diabetes were associated with higher case fatality.

Conclusion-These findings suggest that physical activity may be an important modifiable factor influencing the incidence of ischaemic heart disease and the chance of survival in men without a previous heart attack or stroke. Arrhythmia, increased heart rate, diabetes, and treatment for hypertension are also areas of concern.
\end{abstract}

(Br Heart f 1995;74:324-331)

Keywords: ischaemic heart disease; myocardial infarction; case fatality
It is well established that previous myocardial infarction and age are the strongest determinants of case fatality. ${ }^{12}$ Less is known about other risk factors that may influence survival in the event of a major ischaemic heart disease event. Earlier studies have focused on the three major risk factors, namely, cigarette smoking, hypertension, and increased total cholesterol, and although some studies have indicated that these factors are more likely to predispose to fatal outcome in the event of a heart attack, the findings have been inconsistent. $^{3-5}$ In the few studies that have examined the other coronary risk factors in relation to case fatality, there is a suggestion that diabetes, physical inactivity, and increased heart rate may be associated with increased fatality. ${ }^{6-11}$ This paper examines a range of potential coronary risk factors in relation to case fatality to assess factors that may influence survival in the event of a major ischaemic heart disease event in men with and without previous myocardial infarction or stroke.

\section{Patients and methods}

The British regional heart study is a prospective study of cardiovascular disease involving 7735 men aged 40-59 years at enrolment selected from the age sex registers of one group general practice in each of 24 towns in England, Wales, and Scotland between January 1978 and June 1980 . The criteria for selecting the town, the general practice, and the participants as well as the methods of data collection have been reported. ${ }^{12}$ Research nurses administered to each man a standard $\omega$ questionnaire which included questions on smoking habits, alcohol intake, and medical $O$ history. Several physical measurements were made, and blood samples (non-fasting) were taken for measurement of biochemical and haematological variables. Details of the measurement of serum lipid concentrations have been reported. ${ }^{13}$ Haematocrit was estimated using a Coulter $S$ electronic particle counter (Coulter Electronics, Luton) calibrated daily with Coulter \$C. ${ }^{14}$ The London School of Hygiene sphygmanometer was used to measure blood pressure twice in succession with the participants seated and the arm supported on a cushion. The mean of the two readings was used in the analysis and all blood pressure 
readings were adjusted for observer variation within each town. ${ }^{15}$ The men were classified according to their current smoking status: those who had never smoked, ex-cigarette smokers, and current smokers (at four levels: $1-19,20,21-39$, and $\geqslant 40$ cigarettes/day). Those who had only ever smoked pipe/ cigars were grouped as "never smoked". Excigarette smokers who were currently pipe/cigar smokers were classified as ex-cigarette smokers. Alcohol consumption was recorded using questions on frequency, quantity, and type, similar to those used in the 1978 General Household Survey. The men were classified into five groups based on weekly estimated intake: none, occasional, light, moderate, and heavy. ${ }^{16}$ Moderate drinking was defined as those drinking 16-42 units/week. Heavy drinking was defined as men regularly drinking more than six drinks daily ( $>42$ units/week). The longest held occupation of each man was recorded and coded in accordance with the Registrar General's occupational classification. The men were asked to indicate their usual pattern of physical activity, which included regular walking or cycling, recreational activity, and sporting activity. A physical activity score was derived for each man based on frequency and type of leisure activity. ${ }^{17}$ The men were initially grouped into six broad categories: inactive (686 men), occasional (2345 men), light (1761), moderate (1205), moderately vigorous (1120), and vigorous (513). In this paper, the inactive and occasional activity groups have been combined and the moderately vigorous and vigorous groups have been combined. Forced expiratory volume in $1 \mathrm{~s}\left(\mathrm{FEV}_{1}\right)$ was measured using a Vitalograph spirometer (model J49-B2 Vitalograph Medical Instrumentation, Buckingham) with the participant seated. Two consecutive readings were made $15 \mathrm{~s}$ apart and the maximum of these two readings was used height standardised to $1.73 \mathrm{~m}$, the average height of the men in this study. Heart rate was determined at screening from the three lead orthogonal electrocardiogram (ECG). ${ }^{18}$ The men provided information on parental status (alive/dead) and the cause of death. Parental history of death from heart trouble was defined as men who reported that a parent had died from heart trouble. ${ }^{19}$

\section{PRE-EXISTING DISEASE}

The men were asked to recall a doctor diagnosis of angina or myocardial infarction, diabetes, and a number of other disorders listed on the questionnaire. They were also asked for details about any regular medical treatment they were undergoing including antihypertensive drugs. The World Health Organisation (Rose) chest pain questionnaire was administered to all men at the initial examination $^{20}$ and a three orthogonal lead (ECG) was recorded at rest.

PRE-EXISTING ISCHAEMIC HEART DISEASE The men were separated into four groups according to the evidence of ischaemic heart disease present at screening.

(1) No evidence of ischaemic heart disease on WHO chest pain questionnaire, ECG, or recall of a doctor diagnosis of ischaemic heart disease $(n=5792 ; 74.9 \%)$.

(2) Angina or possible myocardial infarction on WHO chest pain questionnaire or recall of a doctor diagnosis of angina, but without electrocardiographic evidence of myocardial ischaemia or infarction ("symptomatic ischaemic heart disease": $n=696$; $9 \cdot 0 \%$ ).

(3) Electrocardiographic evidence of possible or definite myocardial ischaemia or possible myocardial infarction $(n=819$; $10 \cdot 6 \%$ ).

(4) Men with a previous definite myocardial infarction on ECG or who recalled a doctor diagnosis of a heart attack $(n=428$; $5 \cdot 5 \%)$.

In the analyses, men with pre-existing evidence of ischaemic heart disease consist of men in groups $2-4$.

\section{PRESENCE OF ARRHYTHMIA}

A complex diagnostic tree, which was part of a larger set of criteria used in interpreting the ECG as a whole, was utilised to make the interpretation. ${ }^{21}$ All ECGs in the study were reviewed by an experienced electrocardiographer (PWM) and if any errors in the computer based rhythm interpretation were detected, they were corrected before results were entered into the database. A normal rhythm was defined as sinus rhythm, coronary sinus rhythm, or sinus arrhythmia. All other statements of rhythm were treated as an arrhythmia, for example, sinus rhythm with ventricular extrasystoles. As expected, $97.8 \%$ of the men in the study were in sinus rhythm. Only $0.7 \%$ were in atrial fibrillation which is lower than expected in a general population of this kind.22 At least one ventricular extrasystole was present in the $8 \mathrm{~s}$ recording in 212 men $(2 \cdot 7 \%)$ and 113 (1.5\%) had supraventricular/atrial extrasystoles. Other significant abnormalities occurred with negligible frequency, for example two men were in complete heart block.

\section{FOLLOW UP}

All men irrespective of whether they showed evidence of ischaemic heart disease at initial examination were followed up for all cause mortality and cardiovascular morbidity. ${ }^{23}$ Information on death was collected through the established "tagging" procedures provided by the NHS registers in Southport (England and Wales) and Edinburgh (Scotland). Mortality and major ischaemic heart disease events (fatal and non-fatal) are based on 11.5 years of follow up for each man, and follow up has been achieved for $99 \%$ of the original cohort. As we are concerned with survival in the event of a single myocardial infarction, fatal events in this paper include only those deaths that occurred as the first event in the course of the follow up after initial screening. 
Figure 1 Pre-existing ischaemic heart disease (IHD) and stroke and major ischaemic heart disease event rate/1000/year and case fatality rate. IHD (group 2), symptomatic IHD; IHD (group 3), electrocardiographic evidence of IHD but not definite myocardial infarction (MI).

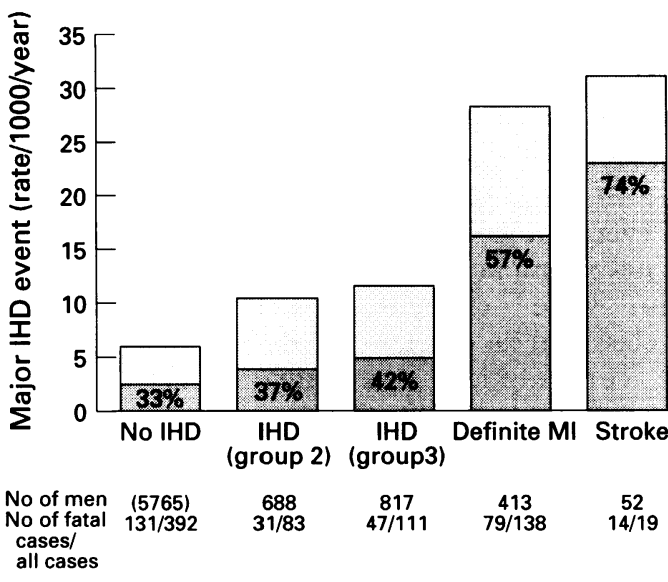

CASE DEFINITIONS FOR MAJOR ISCHAEMIC HEART DISEASE EVENTS

Fatal

Fatal events were defined as death from ischaemic heart disease (International Classification of Diseases, 9th revision (ICD-9), codes 410-414) as the underlying cause and in whom this statement was not contradicted by either the medical history or findings at necropsy. Sudden death for which no other cause was apparent and which was certified as the result of ischaemic heart disease was included in this category.

\section{Non-fatal}

A non-fatal myocardial infarction was one which satisfied at least two of the following criteria: (a) history of severe prolonged chest pain; (b) electrocardiographic evidence of myocardial infarction; and (c) cardiac enzyme changes associated with myocardial infarction. These aspects were ascertained by direct reports from general practitioners and regular case note reviews. Patients who survived a first myocardial infarction for more than 28 days and who died thereafter during follow up were included in the non-fatal group. ${ }^{24}$

\section{Case fatality}

Case fatality is defined as the proportion of these major ischaemic heart disease events in which death occurred during the 28 days after the first event and in which the death certificate recorded ischaemic heart disease (ICD-9 codes 410-414).

\section{STATISTICAL METHODS}

Multiple logistic regression was used to assess simultaneously the factors that influenced fatal outcome in the event of a major ischaemic heart disease event with fatal outcome coded 1 versus non-fatal outcome (code 0 ) as the dependent variable. The odds ratio (OR) obtained from the logistic model represents the odds of dying in the event of a major ischaemic heart disease event. As the case fatality rate is high the ORs differ greatly from the relative risks. Age at time of event was strongly correlated with age at enrolment $(r=0.93)$ and adjustment for age was carried out using age at time of event fitted continu- ously. The men were divided into five groups of about equal numbers based on the total study population for systolic blood pressure, blood cholesterol, high density lipoprotein (HDL) cholesterol, white cell count, and $\mathrm{FEV}_{1}$. The men were divided into five groups on the basis of absolute levels of the risk factor for heart rate and cut off points were used for haematocrit and blood glucose $(\geqslant 46 \%$ and $\geqslant 6.2 \mathrm{mmol} / 1$ respectively) as our earlier reports have shown a threshold effect. ${ }^{1425}$ Adjusted OR for cholesterol, $\mathrm{FEV}_{1}$, and heart rate were obtained by fitting cholesterol, $\mathrm{FEV}_{1}$, and heart rate as four dummy variables for the five levels of each risk factor. Tests for trend were carried out fitting the quantitative variables in their continuous form. In the adjustment, cholesterol, $\mathrm{FEV}_{1}$, and heart rate were fitted as five categorical groups, smoking status as two dummy variables for the three smoking groups (never, ex, current), physical activity as a dichotomous variable (moderately vigorous/vigorous $v$ rest), alcohol as a dichotomous variable (moderate/heavy $v$ rest), and arrhythmia on ECG (yes/no), diabetes (yes/no), and use of antihypertensive treatment (yes/no) as dichotomous variables. Participants with missing values for covariates in the adjustments were excluded from that particular analysis. $P>0.05$ and $\leqslant 0.09$ are considered to be of marginal significance.

\section{Results}

During the follow up period of 11.5 years for each man there were 743 major ischaemic heart disease events, representing an attack rate of 8.4/ $1000 /$ year. Of these, 302 were fatal $(40 \cdot 6 \%)$.

PRE-EXISTING ISCHAEMIC HEART DISEASE AND STROKE

Figure 1 shows the incidence of major ischaemic heart disease events/1000/year and case fatality rate in men by presence of ischaemic heart disease and stroke. The incidence of major ischaemic heart disease events and case fatality tended to increase with increasing grades of ischaemic heart disease and was particularly high in those with definite myocardial infarction or stroke. The stroke group included 15 men with previous myocardial infarction. Men with evidence of ischaemic heart disease on chest pain questionnaire (group 2) showed a small increase in case fatality rate but men with evidence on ECG (group 3) showed a much higher case fatality rate, with a $46 \%$ increase in the odds of dying in the event of an attack compared with that of those with no evidence of ischaemic heart disease at screening (OR = $1.46(95 \%$ confidence interval (CI) 0.96 to $2 \cdot 22)$ ); the difference was of marginal significance $(P=0.08)$. Evidence of definite myocardial infarction and history of stroke were associated with high case fatality rates (57\% and $74 \%$ respectively) compared with $33 \%$ in those without evidence of pre-existing ischaemic heart disease $(\mathrm{OR}=2.66(95 \% \mathrm{CI}$ 1.79 to 3.97$)$ and $\mathrm{OR}=5.58(95 \%$ CI 1.93 to $16 \cdot 11)$ respectively; both $P<0.001$ ) 
Figure 2 Age at time of event and case fatality rate in men with and without previous myocardial infarction/stroke.

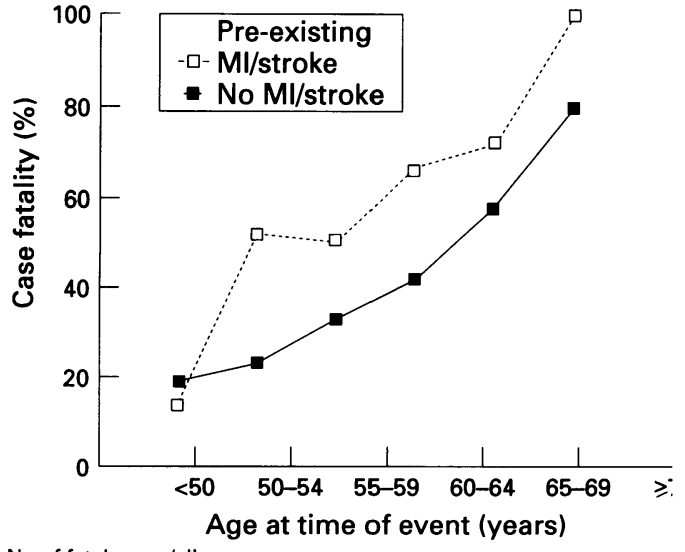

No of fatal cases/all cases

AGE AT TIME OF EVENT

It is well established that age is one of the strongest determinants of survival in the event of an attack. ${ }^{1}$ Figure 2 shows the case fatality rate by age at time of event in men with and without pre-existing myocardial infarction or stroke. Men with pre-existing myocardial infarction or stroke had higher case fatality rates than men without either condition at all ages except the youngest, where the number of cases was small. The chance of dying increased significantly with increasing age in both groups $(P<0.0001)$ and the trend was similar in each (logistic regression coefficient $b=0.10$ and $b=0.09$ for those with and without myocardial infarction or stroke respectively). In men with no pre-existing myocardial infarction or stroke who suffered a heart attack before the age of 50 only about $20 \%$ were fatal compared with over $50 \%$ in those aged $65-69$ and up to $80 \%$ in those aged 70 and older. In those with previous myocardial infarction or stroke, excluding those who suffered an attack before the age of 50 , case fatality was at least $50 \%$ at $50-54$ years and this increased with age.

OTHER DETERMINANTS OF CASE FATALITY

Because of the strong influence of previous myocardial infarction or stroke on dying in the event of a heart attack $(59 \%$ in the combined group with stroke or definite myocardial infarction compared with $37 \%$ in the rest of the men; age adjusted OR 2.64 (95\% CI 1.8 to 3.8$)$ ) and because of the interest in determining factors that may be associated with survival in the event of an initial major ischaemic heart disease event we have examined men with and without previous myocardial infarction or stroke separately in the following analyses.

Table 1 Incidence of major ischaemic heart disease (IHD) events, case fatality rate and odds ratio by pre-existing disease, personal characteristics, and biological factors in men without a previous myocardial infarction or stroke

\begin{tabular}{|c|c|c|c|}
\hline Risk factors & $\begin{array}{l}\text { Major IHD event } \\
\text { (rate/1000/year) (n) }\end{array}$ & $\begin{array}{l}\text { Case }(\%) \\
\text { fatality }(n)\end{array}$ & $\begin{array}{l}\text { Odds ratio } \\
\text { ( } 95 \% \text { confidence intervals) } \\
\text { (age adjusted) }{ }^{*}\end{array}$ \\
\hline $\begin{array}{l}\text { Arrhythmia } \\
\text { No (6929) } \\
\text { Yes (333) }\end{array}$ & $\begin{aligned} 6 \cdot 8(542) \\
11 \cdot 2(43)\end{aligned}$ & $\begin{array}{l}34(185) \\
56(24)\end{array}$ & $\begin{array}{l}1.00 \\
2 \cdot 18(1 \cdot 13 \text { to } 4 \cdot 14) \dagger\end{array}$ \\
\hline $\begin{array}{l}\text { Antihypertensive } \\
\text { No (7002) } \\
\text { Yes }(268)\end{array}$ & $\begin{aligned} & 6 \cdot 6(534) \\
& 16.9(52)\end{aligned}$ & $\begin{array}{l}34(182) \\
52(27)\end{array}$ & $\begin{array}{l}1.00 \\
1.79(1.00 \text { to } 3.25) \dagger\end{array}$ \\
\hline $\begin{array}{l}\text { Diabetes } \\
\text { No }(7173) \\
\text { Yes }(97)\end{array}$ & $\begin{aligned} 6 \cdot 9(568) \\
16 \cdot 1(18)\end{aligned}$ & $\begin{array}{l}35(199) \\
56(10)\end{array}$ & $\begin{array}{l}1.00 \\
2.46(0.91 \text { to } 6.68) \int\end{array}$ \\
\hline $\begin{array}{l}\text { Smoking } \\
\text { Never }(1758) \\
\text { Ex smoker }(2526) \\
\text { Current }(2971)\end{array}$ & $\begin{array}{l}3 \cdot 9(80) \\
6 \cdot 4(186) \\
9 \cdot 3(319)\end{array}$ & $\begin{array}{l}29(23) \\
37(68) \\
37(118)\end{array}$ & $\begin{array}{l}1.00 \\
1.31(0.72 \text { to } 2.34) \\
1.61(0.92 \text { to } 2 \cdot 79)\end{array}$ \\
\hline $\begin{array}{l}\text { Physical activity } \\
\text { None/Occasional (2787) } \\
\text { Light (1671) } \\
\text { Moderate (1145) } \\
\text { Moderately vigorous/vigorous (1570) }\end{array}$ & $\begin{array}{l}8 \cdot 7(278) \\
7 \cdot 6(146) \\
4 \cdot 9(65) \\
4 \cdot 9(88)\end{array}$ & $\begin{array}{l}39(109) \\
37(54) \\
37(24) \\
22(19)\end{array}$ & $\begin{array}{l}\text { Moderately vigorous/vigorous } v \text { rest } \\
0.46(0.26 \text { to } 0.81) \ddagger\end{array}$ \\
\hline $\begin{array}{l}\text { Alcohol } \\
\text { None/Occasional (2136) } \\
\text { Light (2408) } \\
\text { Moderate (1932) } \\
\text { Heavy (788) }\end{array}$ & $\begin{array}{l}7 \cdot 6(186) \\
6 \cdot 2(172) \\
7 \cdot 2(161) \\
7 \cdot 3(66)\end{array}$ & $\begin{array}{l}38(71) \\
41(71) \\
30(48) \\
29(19)\end{array}$ & $\begin{array}{l}\text { Moderate/heavy } v \text { rest } \\
0.73(0.51 \text { to } 1.03) \oint\end{array}$ \\
\hline $\begin{array}{l}\mathrm{FEV}_{1}(\mathrm{l}) \\
<2 \cdot 81(1369) \\
2 \cdot 82-3 \cdot 20(1384) \\
3 \cdot 21-3 \cdot 53(1468) \\
3 \cdot 54-3 \cdot 86(1460) \\
\geqslant 3 \cdot 87(1512)\end{array}$ & $\begin{array}{l}10 \cdot 2(161) \\
7 \cdot 7(122) \\
8 \cdot 0(135) \\
5 \cdot 1(85) \\
4 \cdot 5(78)\end{array}$ & $\begin{array}{l}43(70) \\
38(46) \\
29(39) \\
36(31) \\
26(20)\end{array}$ & $\begin{array}{l}(Q 5 v Q 1) \\
0.67(0.35 \text { to } 1.30) \\
\text { Test for trend } \\
P=0.06\end{array}$ \\
\hline $\begin{array}{l}\text { Cholesterol }(\mathrm{mmol} / \mathrm{l}) \\
<5 \cdot 5(1584) \\
5 \cdot 5-5 \cdot 9(1312) \\
6 \cdot 0-6 \cdot 4(1420) \\
6 \cdot 5-7 \cdot 1(1579) \\
\geqslant 7 \cdot 2(1375)\end{array}$ & $\begin{array}{r}4 \cdot 2(76) \\
5 \cdot 7(86) \\
6 \cdot 5(107) \\
7 \cdot 5(136) \\
11 \cdot 4(181)\end{array}$ & $\begin{array}{l}42(32) \\
49(42) \\
29(31) \\
36(49) \\
30(55)\end{array}$ & $\begin{array}{l}(\mathrm{Q} 5 v \mathrm{Q} 1) \\
0 \cdot 70(0 \cdot 39 \text { to } 1 \cdot 28) \\
\text { Test for trend } \\
\mathrm{P}=0.09\end{array}$ \\
\hline $\begin{array}{l}\text { Heart rate (beats/min) } \\
<60(1349) \\
60-69(2332) \\
70-79(1993) \\
80-89(962) \\
90(593)\end{array}$ & $\begin{array}{l}5 \cdot 2(81) \\
6 \cdot 1(163) \\
8 \cdot 0(183) \\
7 \cdot 3(81) \\
10 \cdot 3(70)\end{array}$ & $\begin{array}{l}31(25) \\
40(65) \\
28(52) \\
42(34) \\
41(29)\end{array}$ & $\begin{array}{l}(\geqslant 90 v<60) \\
1.91(0.96 \text { to } 3 \cdot 78) \\
\text { Test for trend } \\
P=0.15\end{array}$ \\
\hline
\end{tabular}

${ }^{*}$ Fatal $v$ non-fatal -that is odds of dying in the event of a major IHD event adjusted for age at the time of the event; $+\mathrm{P}<0.05$ $\ddagger P<0.01 ; \S P=0.08 ; P=0.09$.

$\mathrm{FEV}_{1}$, forced expiratory volume in $1 \mathrm{~s} ; \mathrm{Q} 5 v \mathrm{Q} 1$, quintile $5 v$ quintile 1 
Table 2 Coronary risk factors and adjusted odds of dying (fatal $v$ non-fatal) in the event of a heart attack in men without a previous myocardial infarction or stroke

\begin{tabular}{|c|c|}
\hline & $\begin{array}{l}\text { Odds ratio } \\
\text { ( } 95 \% \text { confidence intervals) * }\end{array}$ \\
\hline $\begin{array}{l}\text { Arrhythmia (Yes/No) } \\
\text { Antihypertensive treatment } \\
\text { Diabetes (Yes/No) }\end{array}$ & $\begin{array}{l}1.93(0.97 \text { to } 3.80) \ddagger \\
1.97(1.06 \text { to } 3.67) \ddagger \\
2.61(0.92 \text { to } 7.60) \$\end{array}$ \\
\hline \multicolumn{2}{|l|}{ Smoking } \\
\hline Exsmoker ( $v$ never) & $\begin{array}{l}1.27(0.68 \text { to } 2.36) \\
1.64(0.90 \text { to } 3.02)\end{array}$ \\
\hline (Moderately vigorous/vigorous $v$ rest) & $\begin{array}{l}0.53(0.30 \text { to } 0.95) t \\
\text { rest) }\end{array}$ \\
\hline (Moderate/heavy $v$ rest) & $0.66(0.44$ to 0.96$) \dagger$ \\
\hline \multicolumn{2}{|l|}{ FEV $_{1}$ (quintiles) } \\
\hline 1 & 1.00 \\
\hline 2 & $1.04(0.60$ to 1.79$)$ \\
\hline 3 & $0.89(0.52$ to 1.53$)$ \\
\hline 4 & $1.20(0.64$ to 2.20$)$ \\
\hline 5 & $0.90(0.45$ to 1.79$)$ \\
\hline Test for trend & $P=0.61$ \\
\hline \multicolumn{2}{|l|}{ Cholesterol (quintiles) } \\
\hline 1 & 1.00 \\
\hline 2 & $1.20(0.60$ to $2 \cdot 41)$ \\
\hline 3 & $0.57(0.28$ to 1.14$)$ \\
\hline 4 & $0.76(0.41$ to 1.44$)$ \\
\hline 5 & $0.70(0.39$ to 1.28$)$ \\
\hline Test for trend & $P=0 \cdot 17$ \\
\hline \multicolumn{2}{|l|}{ Heart rate (beats/min) } \\
\hline$<60$ & 1.00 \\
\hline $\begin{array}{l}60-69 \\
70-79\end{array}$ & $1.66(0.90$ to $3 \cdot 10)$ \\
\hline $\begin{array}{l}70-79 \\
80-80\end{array}$ & $0.90(0.48$ to 1.72$)$ \\
\hline $\begin{aligned} & 80-89 \\
\geqslant & 90\end{aligned}$ & $1.43(0.34$ to 2.94$)$ \\
\hline $\begin{array}{l}\geqslant 90 \\
\text { Test for trend }\end{array}$ & $\begin{array}{l}2.03(0.98 \text { to } 4.39) \ddagger \\
P=0.15\end{array}$ \\
\hline
\end{tabular}

^ Adjusted for age at time of event, arrhythmia, diabetes, antihypertensive treatment, physical activity, moderate/heavy drinking, cigarette smoking, $\mathrm{FEV}_{1}$, cholesterol, and heart rate. The analysis included 568 cases (201 fatal) with complete data on all covariates. $\dagger \mathrm{P}<0.05$;
$\mathrm{FEV} 1$, forced expiratory volume in $1 \mathrm{~s}$.

\section{PRE-EXISTING DISEASE, PERSONAL}

CHARACTERISTICS, AND BIOLOGICAL FACTORS In men with no previous myocardial infarction/stroke $(n=7270)$ we examined the relation between case fatality and factors associated with the incidence of ischaemic heart disease in this study, namely, pre-existing ischaemic heart disease (groups 2 and 3), arrhythmia on ECG, antihypertensive drugs, diabetes, smoking, physical activity, alcohol intake, obesity, parental history, social class, $\mathrm{FEV}_{1}$, total cholesterol, blood glucose, systolic blood pressure, HDL cholesterol, white cell count, heart rate, and haematocrit adjusting for age at time of event. Table 1 shows the incidence of major ischaemic heart disease events $/ 1000 /$ year and case fatality. It also shows the OR of dying in the event of a major heart attack adjusted for age at time of event. Only factors that were significant or marginally significant $(P<0.09)$ after adjustment for age, namely, arrhythmia on ECG, antihypertensive treatment, diabetes, moderately vigorous/vigorous levels of physical activity, moderate/heavy drinking, $\mathrm{FEV}_{1}$, cholesterol, and increased heart rate are presented. Arrhythmia and diabetes were associated with over a twofold increase in the odds of dying in the event of a heart attack (OR $=2 \cdot 18$ and 2.46 respectively). Antihypertensive treatment was associated with nearly a twofold increase in the odds of dying. Current smokers showed higher case fatality than those who had never smoked; the difference was of marginal significance $(P=0.09)$. Moderately vigorous/vigorous levels of physical activity were associated with a decrease in the incidence of a major ischaemic heart disease event and a significant decrease in the case fatality rate $(O R=0.46, P<0.05)$. Although moderate/heavy drinking was not associated with a decrease in the incidence of major ischaemic heart disease events compared with those who did not drink, or were occasional or light drinkers, it was associated with lower case fatality; the difference was of marginal significance $(O R=0.73 ; P=0.08)$. Lung function was inversely associated with the incidence of major ischaemic heart disease and case fatality $(P=0.06)$. Although increased total cholesterol $(\geqslant 7.2 \mathrm{mmol} / \mathrm{l})$ is associated with a significant increase in the incidence of major ischaemic heart disease events, case fatality tended to be lower than in those in the lower cholesterol groups (test for trend $P=0.09)$. Pre-existing ischaemic heart disease (groups 2 and 3), obesity (body mass index $\geqslant 28 \mathrm{~kg} / \mathrm{m}^{2}$ ), parental history, social class, systolic blood pressure, HDL cholesterol, white cell count, increased blood glucose, and haematocrit were not associated with case fatality after adjustment for age at time of event.

INDEPENDENT PREDICTORS OF CASE FATALITY As many of the factors in table ${ }^{1}$ are interrelated, we have examined the OR for death in the event of a heart attack (fatal $v$ non-fatal) for these factors adjusting in addition for each of the other factors presented in table 1. Data on all covariates were available in 568 cases (201 fatal). Antihypertensive treatment, moderately vigorous/vigorous levels of physical activity, and moderate/heavy alcohol intake remained significantly associated with case fatality (all $\mathrm{P}<0.05$ ) (table 2). When moderate drinkers were separated from heavy drinkers it was seen that moderate drinkers showed significantly lower odds of dying in the event of a heart attack (OR $=0.61$ (95\% CI 0.38 to 0.96$)$ ). Heavy drinkers showed a small non-significant decrease $(\mathrm{OR}=0.76$ (95\% CI 0.41 to $1 \cdot 48$ ). Arrhythmia showed nearly a twofold increase in odds of dying; the difference was of marginal significance $(P=$ $0.06)$. Diabetes was associated with over a twofold increase in odds of dying $(P=0.07)$. Adjustment for the other variables made little difference to the smoking association; indeed, the odds of dying for current smokers increased slightly, but the difference became non-significant $(P=0.11)$ because of the smaller number of cases involved. The inverse association with case fatality seen for $\mathrm{FEV}_{1}$ and blood cholesterol was attenuated after adjustment for the other factors and the trends were no longer significant. Men with an increased heart rate showed a more than twofold increase in odds of dying compared with that of men with heart rate, <60 beats/min; the difference was of marginal significance $(P=0 \cdot 06)$. No consistent trend was seen between the other heart rate groups $(P=0 \cdot 15)$.

MEN WITH PREVIOUS DEFINITE MYOCARDIAL INFARCTION AND STROKE

Factors independently associated with case 
fatality were analysed separately in men with previous definite myocardial infarction/stroke. Although cigarette smoking status was not significant, it was also examined because of the magnitude of the association (data available on request). After adjusting for age alone, presence of arrhythmia was significantly and strongly associated with case fatality $(O R=6.72(95 \%$ CI 1.43 to $31 \cdot 20)$ ). Presence of diabetes and use of antihypertensive treatment were also associated with case fatality but the differences were not significant $(O R=1.46(95 \% \mathrm{CI} 0.67$ to 3.15$)$ and $\mathrm{OR}=2.01(95 \%$ CI 0.40 to 9.87$)$ respectively). Moderate/heavy drinking showed a slight increase in the odds of dying unlike that seen in men without previous myocardial infarction/stroke (OR $=1.19(95 \%$ CI 0.56 to $2 \cdot 51)$ ). Moderately vigorous/vigorous levels of physical activity were associated with only a small decrease in case fatality $(O R=0.78$ (95\% CI 0.49 to $2 \cdot 02)$ ). Cigarette smoking and increased heart rate showed no association $(\mathrm{OR}=1.16$ and 1.00 respectively). After adjusting for each of the other factors, the strong and positive association with arrhythmia remained $(O R=8.24(95 \%$ CI 1.67 to 40.44)). Diabetes and antihypertensive treatment were positively associated with case fatality $(O R=1.51$ and $O R=2.92$; not significant). Adjustment for the other factors increased the positive association seen with moderate/heavy drinking, although the difference remained non-significant ( $O R=$ 1.55). When moderate and heavy drinkers were separated the increased odds were seen for moderate and heavy drinkers (OR $=1.57$ and 1.55 respectively). No association was seen with moderately vigorous/vigorous activity. Other factors not associated with case fatality in men without myocardial infarction/ stroke were also examined in those with previous myocardial infarction/stroke but none were associated with case fatality in these men.

\section{Discussion}

Although factors affecting ischaemic heart disease incidence have been extensively studied, less is known about those that determine the likelihood of death in the event of myocardial infarction. In this study of a representative sample of middle aged British men, overall case fatality rates were broadly similar to those described in comparable community based studies. ${ }^{26-29}$ Age at the time of event and a past history of myocardial infarction or stroke were the strongest determinants of case fatality. In men without a previous myocardial infarction, the presence of arrhythmia or increased heart rate $(\geqslant 90$ beats/min), diabetes, or antihypertensive drug treatment were independently associated with an increased risk of dying in the event of a heart attack. Conversely, moderately vigorous or vigorous levels of physical activity were independently associated with an increased chance of survival in the event of a heart attack. Moderate drinking, although not strongly related to the incidence of major ischaemic heart disease events, was also associated with an increased chance of survival after myocardial infarction. Systolic blood pressure, white cell count, HDL cholesterol, social class, parental history, cholesterol, blood glucose, and haematocrit showed no relation with case fatality, although all have been shown to be independent risk factors affecting the incidence of coronary disease. In men with a previous myocardial infarction or stroke, the presence of arrhythmia was a particularly strong determinant of case fatality. In this group, the protective effects of physical activity and alcohol intake were not apparent.

Although the influences of several factors on case fatality have been examined, raising the possibility of false positive associations, the most important findings are consistent with earlier reports. The influence of age on case fatality has been previously described ${ }^{3}$ and appears to influence both inhospital and subsequent mortality..$^{30}$ The influence of preexisting ischaemic heart disease, especially when associated with resting electrocardiographic abnormality (either the presence of $Q$ waves or to a lesser extent ST-T wave changes suggestive of myocardial ischaemia), on case fatality was also observed in the Worcester heart study. ${ }^{30}$ The adverse influence of previous completed stroke on survival after myocardial infarction has been previously described. ${ }^{3}$ Diabetes was associated with a noticeable increase in the odds of case fatality in men with or without a previous myocardial infarction. Similar increases in case fatality have been described in American $^{6-8}$ and British studies. ${ }^{9}$ The increase in case fatality seems to affect inhospital and late mortality ${ }^{78}$ and may be the result of a higher incidence of severe heart failure and cardiogenic shock in diabetic patients. ${ }^{78}$ Increased heart rate was strongly associated with case fatality in the Framingham study ${ }^{11}$ and was also described in the Goteborg study. ${ }^{4}$ Whether this reflects a relation between low physical fitness or early cardiac disease with case fatality remains to be established. Arrhythmia was associated with an increase in case fatality, particularly in men with a previous myocardial infarction or stroke. Although the presence of atrial fibrillation is well known to increase case fatality, ${ }^{31}$ this accounted for only a minority (14\%) of arrhythmias in the present study, with supraventricular and ventricular extra systoles comprising almost all the remainder. More detailed analyses suggest that the increase in case fatality is associated with all of these arrhythmias and not only atrial fibrillation.

The relation between antihypertensive treatment and case fatality is striking and seems to apply in men with or without a previous heart attack. The reason for the relation is not clear. It does not seem to be a manifestation of hypertension per se, as blood pressure level at screening showed no relation with case fatality. The effect may relate to drug treatment, or to other factors 
influencing the likelihood of receiving drug treatment, particularly the severity of hypertension and the presence of cardiac involvement. In the present study it is not possible to determine whether any particular drug type was associated with the increase in case fatality. Serum potassium concentration was not related to case fatality, however, suggesting that adverse consequences of diuretic induced hypokalaemia ${ }^{32}$ were not responsible.

Of the well defined modifiable risk factors for ischaemic heart disease, physical inactivity is the one most strongly related to case fatality. This relation has been described in one previous study. ${ }^{10}$ The protective effect of physical activity was only observed in men engaging in moderately vigorous or vigorous levels of activity - that is, frequent sporting activities (two to three times a week) or sporting activity at least once a week combined with frequent recreational activity (walking, gardening). These levels of physical activity are higher than those associated with protection against incident ischaemic heart disease. ${ }^{17}$ The restriction of the effect to men with no previous definite heart attack or stroke is consistent with our earlier observation that the effect of physical activity on incidence of ischaemic heart disease is most profound in men without pre-existing disease. ${ }^{17}$ If causal, this effect may reflect anatomical or physiological consequences of greater physical fitness, including improved formation of cardiac collateral vessels, increased cardiac stroke volume, and changes in thrombogenic and fibrinolytic factors. ${ }^{33} 34$

Moderate and heavy alcohol intake may also be associated with lower case fatality rates from myocardial infarction, particularly in men with no previous history of myocardial infarction. This finding, which requires confirmation in other studies, may reflect the favourable effects of alcohol on platelet aggregation ${ }^{35}$ and fibrinolytic factors. ${ }^{36}$ In men with a previous myocardial infarction, however, moderate or heavy alcohol intake seems to be associated with an increased case fatality rate. Total blood cholesterol and cigarette smoking, although powerful determinants affecting the incidence of ischaemic heart disease in individuals, had little influence on case fatality from myocardial infarction in this study.

The design of this study did not allow us to examine the effects of treatment on case fatality, particularly that of the increasing use of aspirin and thrombolytic drugs in the acute phase of myocardial infarction since the late 1980 s. No conspicuous change in case fatality was apparent during the years of follow up between 1980 and 1992, and particularly between the last 4 years and the preceding 8 years. However, this is not necessarily surprising. Despite its strong influence on case fatality in clinical trials ${ }^{37}$ the use of thrombolytic treatment in the population has so far been limited $^{38}$ and its impact on case fatality from myocardial infarction in the general population is therefore likely to be small.

\section{Conclusions}

While many factors influence the incidence of major ischaemic heart disease, relatively few factors influence case fatality and fewer still are potentially amenable to modification. Of particular importance is physical activity, which at moderately vigorous or vigorous levels may protect against fatal events, as well as reducing incidence, in men with no previous myocardial infarction or stroke. This finding strengthens the case for encouraging physical activity in middle aged men free of previous heart attack or stroke. The implications of the association between moderate alcohol intake and lower case fatality are less clear cut. Moderate alcohol intake is not associated with a reduced incidence of ischaemic heart disease nor with low levels of all cause mortality. The overall benefits, unlike those for increased physical activity, do not suggest that such an alcohol intake should be recommended for the reduction of case fatality in the event of a heart attack. In men with evidence of a previous myocardial infarction or stroke, the incidence of heart attack is four times as high as in the rest of the cohort and the case fatality rate almost twice as high. At these levels of incidence and case fatality, neither physical activity nor moderate alcohol intake show any protective effect against death in the event of a heart attack and arrhythmia is the factor most markedly associated with case fatality.

The British Regional Heart Study is a British Heart Foundation Research Group and is also supported by the Department of Health and The Stroke Association.

1 Petch MC. Myocardial infarction. In: Julian DG, Camm AI, Fox ICM, Hall RIC, Poole-Wilson PA, eds. Diseases AJ, Fox ICM, Hall RJC, Poole-Wilson PA, eds. Diseases of the heart London: Bailliere Tindall, 1989:1157-91.
Blackburn $\mathrm{H}$. Progress in the epidemiology and preven Blackburn H. Progress in the epidemiology and prevenRomo M. Factors related to sudden death in acute ischaemic heart disease. Acta Med Scand 1972;547 (suppl):7-92.

4 Tibblin G, Wilhelmsen L, Wrko L. Risk factors for myocardial infarction and death due to ischaemic heart disease and other causes. Am f Cardiol 1975;35:514-22.

5 Svardsudd K, Tibblin G. Mortality and morbidity during 13.5 years follow-up in relation to blood pressure. Acta Med Scand 1979;205:483-92.

6 Abbott RD, Donaghue RP, Kannel WB, Wilson PWF. The impact of diabetes mellitus on survival following myocardial infarction in men versus women. The
Framingham study. $\mathscr{f} A M A 1988 ; 260: 3456-60$.

7 Donahue RP, Goldberg RJ, Chen Z, Gore JM, Alpert JS The influence of sex and diabetes mellitus on survival following acute myocardial infarction: a communitywide perspective. 7 Clin Epidemiol 1993;46:245-52.

8 wide perspective. $\mathcal{F}$ Clin Epidemiol 1993;46:245-52. Hahn LP. Trends in prevalence of diabetes mellitus in patients with myocardial infarction and effect of diabetes on survival. The Minnesota heart survey. Diabetes Care 1991;14:537-43.

9 Yudkin JS, Oswald GA. Determinants of hospital admission and case fatality in diabetic patients with myocardial infarction. Diabetes Care 1988;11:351-8.

10 Eriksenn J. Physical fitness and coronary heart disease $\mathbb{D}$ morbidity and mortality: a prospective study in apparently healthy middle-aged men. Acta Med Scand 1986; (suppl 711):189-92.

11 Kannel WB, Kannel C, Paffenbarger RS, Cupples LA. Heart rate and cardiovascular mortality: the Framingham study. Am Heart $₹$ 1987;113:1489-94.

12 Shaper AG, Pocock SJ, Walker M, Cohen NM, Wale CJ, Thomson AG. British regional heart study: cardiovascular risk factors in middle-aged men in 24 towns. $B M F$ 1981;283:179-86.

13 Thelle DS, Shaper AG, Whitehead TP, Bullock DG, Ashby D, Patel I. Blood lipids in middle-aged British Ashby D, Patel 1. Blood lipids in

14 Wannamethee G, Shaper AG, Whincup PH. Ischaemic heart disease: association with haematocrit in the British reart disease: association with haematocrit in the British regional heart

15 Bruce NG, Shaper AG, Walker M, Wannamethee G. 
Observer bias in blood pressure studies. $f$ Hypertens 1988;6:375-80.

16 Shaper AG, Wannamethee G, Walker M. Alcohol and mortality in British men: explaining the U-shaped curve. Lancet 1988;ii: $1267-73$.

17 Shaper AG, Wannamethee G, Weatherall R. Physica activity and ischaemic heart disease in middle-aged men. Br Heart f 1991;66:384-94

18 Shaper AG, Wannamethee G, Macfarlane PW, Walker $M$ Heart rate, ischaemic heart disease and sudden cardiac death in middle-aged British men. Br Heart $\mathcal{F} 1993 ; 70$. 49-55.

19 Phillips AN, Shaper AG, Pocock SJ, Walker M. Parental death from heart disease and the risk of heart attack. Eur Heart $₹$ 1988;9:243-51.

20 Cook DG, Shaper AG, Macfarlane PW. Using the WHO (Rose) angina questionnaire in cardiovascular epidemiology studies. Int $f$ Epidemiol 1989;18:607-13.

21 Macfarlane PW, Watts MP, Peden J, Lennox G, Lawrie TDV. Computer assisted electrocardiogram interpretation. Br 7 Clin Equip 1976;1:61-70.

22 Dunn $M$, Alexander J, de Silva R, Hildner F. Anti-thrombotic therapy in atrial fibrillation. Chest 1989;95. 118-27S.

23 Walker M, Shaper AG. Follow-up of subjects in prospective studies based in general practice. $\mathcal{F} R$ Coll Gen Pract 1984;34:365-70.

24 World Health Organisation. Proposal for the multinational monitoring of trends and determinants in cardiovascular disease (MONICA) project and protocol. Geneva: Cardiovascular Disease Unit, World Health Organisation, 1983

25 Perry IJ, Wannamethee G, Whincup PH, Shaper AG. Asymptomatic hyperglycaemia and ischaemic heart disease. $¥$ Epidemiol Community Health 1994;48:538-42.

26 Perez G, Marrugat J, Sala J. Myocardial infarction in Girona, Spain: attack rate, mortality rate and 28-day case fatality in 1988 . Regicor Study Group. $\mathcal{f}$ Clin case fatality in 1988. Re

27 Evans AE, Paterson CC, Mathewson Z, McCrum EE Mcllmoyle EL. Incidence, delay and survival in Belfast
MONICA project coronary event register. Prev Epid Sante Publ 1990;38:419-27.

28 Dobson AJ, Gibberd EW, Leeder SR, et al. Ischaemic heart disease in the Hunter region of New South Wales, heart disease in the Hunter region of New South Wales,

29 Beaglehole R, Bonita R, Jackson R, Stewart A, Sharpe M, Fraser GE. Trends in coronary heart disease event rates in New Zealand. Am $\mathcal{F}$ Epidemiol 1984;120:225-35.

30 Goldberg RJ, Gore JM, Gurwitz JH, et al. The impact of age on the incidence and prognosis of initial acute myocardial infarction: the Worcester heart attack study. Am Heart $\mathcal{F}$ 1989;117:543-9.

31 Goldberg RJ, Seeley D, Becker RC, et al. Impact of atrial fibrillation on the in-hospital and long-term survival of patients with acute myocardial in wide perspective. Am Heart f 1990;119:996-1001.

32 Tannen RL. Diuretic induced hypokalaemia. Kidney Int 1985;28:988-1000.

33 Fagard RH. Impact of different sports and training on cardiac structure and function. Cardiol Clin 1992;10. 241-56.

34 Ferguson EW, Bernier LL, Banta GR, Schoomaker EB. Effects of exercise and conditioning on clotting and fibrinolytic activity in men. $f$ Appl Physiol 1987;62: 1416-21.

35 Renaud S, Beswick AD, Fehily AM, Sharp DS, Elwood PC. Alcohol and platelet aggregation: the Caerphilly prospective heart disease study. Am $\mathcal{F}$ Clin Nutr 1992; 55:1012-7.

36 Hendrichs HFG, Veenstra J, Veltshuisnte Wierik EGM Shaafsma J, Kluft C. Effect of moderate dose of alcoho with evening meal on fibrinolytic factors. BMF 1994; 308:1003-6.

37 AIMS Trial Study Group. Effect of intravenous APSAC on mortality after acute myocardial infarction: preliminary report of a placebo-controlled trial. Lancet 1988;i: $545-9$.

38 Gray D, Keating NA, Murdock J, Skene AM, Hampton JR. Impact of hospital thrombolysis policy on out-ofhaspital response to sus;
The 1996 Annual Meeting of the British Cardiac Society will take place at the Scottish Exhibition \& Conference Centre, Glasgow from 7 to 9 May.

The sixtieth annual meeting of the Japanese Circulation Society will take place from 19 to 21 March 1996 at the Royal Hotel, 5-3-68 Nakanoshima, Kita-ku, Osaka 530, Japan. For further information please contact Kunio Miyatake MD, National Cardiovascular Centre, 5-7-1 Fujishiro-dai, Suita, Osaka 565, Japan (tel: +81 6873 0707; fax: +81 6 873 0708).
Cardiac pacing: the service should be local as the anaesthetic. $D$ Pitcher

The word "as" was omitted by the printers from the title of this editorial $(\mathrm{Br}$ Heart $\mathcal{F} 1995 ; 74: 7-8)$. The correct title is "Cardiac pacing: the service should be as local as the anaesthetic." 